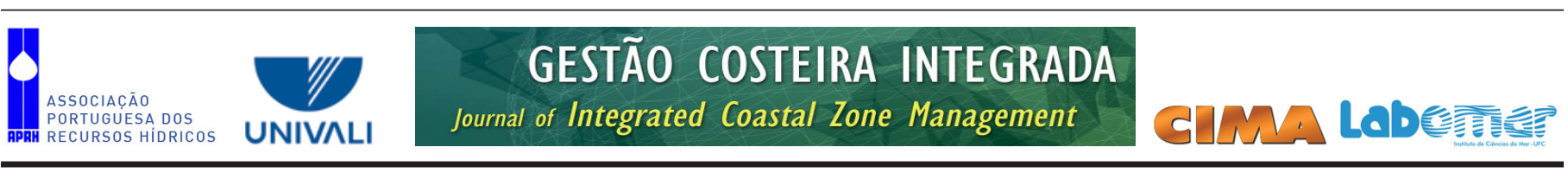

http://www.aprh.pt/rgci/pdf/rgci-408_Bitencourt.pdf | DOI:10.5894/rgci408

\title{
Percepção das Populações Costeiras sobre os Efeitos dos Eventos Adversos no Extremo Sul de Santa Catarina - Brasil *
}

\author{
Perception of Coastal Populations on the Effects Adverse Events in the \\ Extreme South of Santa Catarina - Brazil
}

\author{
Neres de Lourdes da Rosa Bitencourt ${ }^{\circledR, 1}$, Isa de Oliveira Rocha ${ }^{1}$
}

\section{RESUMO}

Este trabalho aborda os eventos naturais extremos ocorrentes no litoral de Santa Catarina e tem como objetivo apresentar e analisar a percepção dos atores sociais por meio dos relatos orais de moradores de áreas atingidas por esses eventos, que ocorreram tanto no meio rural quanto no meio urbano. Investiga também como está organizada a administração municipal no sentido de alertar a população sobre a ocorrência desses eventos adversos. A pesquisa foi realizada nos municípios de Balneário Gaivota, Passo de Torres, Santa Rosa do Sul, São João do Sul e Sombrio. A metodologia adotada consistiu em entrevistas abertas com pessoas que vivem nesses locais e que foram atingidas por esses eventos e com a administração dos municipios da área de estudo. Inclui ainda levantamento bibliográfico e documental. Entre os resultados, destacam-se depoimentos sobre ventos fortes com chuva e granizo e enchentes com inundaçóes que atingiram a área de estudo. Os maiores impactos foram observados na área rural, e as áreas mais atingidas foram as lavouras de banana, arroz e fumo. Houve também prejuízos com danos em residências e instalaçóes agrícolas. Os resultados mostraram a necessidade de as administraçóes municipais estarem preparadas e desenvolverem açóes diferenciadas para atuarem tanto no meio rural quanto no urbano.

Palavras-Chave: Litoral de Santa Catarina, Atores Sociais, Desastres Naturais.

\section{ABSTRACT}

This study addresses the extreme natural events occurring on the coast of Santa Catarina. These events affect rural and urban areas therefore the purpose of this research is to analyse the residents and social actors perception about the events. It also investigates how the municipal management is organized to warn the population of weather adversities. The target areas are the cities of Balneário Gaivota, Passo de Torres, Santa Rosa do Sul, São João do Sul and Sombrio. The method included unstructured interviews with residents and municipal administration of the cities affected by natural events. Besides, it incorporated bibliographic and documentary investigation. The main findings comprise people's statement about strong winds with rain and hail, floods and inundation in the study area. The hugest impacts were identified in the rural areas with losses of banana, rice and tobacco crops. Furthermore, several damages occurred in housing and agricultural buildings. The results showed the necessity of local government preventative schemes and the development of different action to rural and urban areas as they have distinct realities.

Keywords: Coast of Santa Catarina, Social Actors, Natural Disasters.

@ - Corresponding author

1 - Universidade do Estado de Santa Catarina - UDESC, Programa de Pós-Graduação em Planejamento Territorial e Desenvolvimento Socioambiental MPPT, Av. Madre Benvenuta, 2007, Itacorubi, CEP: 88035-001, Florianópolis, SC, Brasil.E-mail: Bitencourt nb.gestaoambiental@gmail.com, Rocha isa@ udesc.br. 


\section{INTRODUÇÃO}

Nas últimas décadas, tem aumentado de forma significativa a frequência de ocorrência de desastres naturais em várias partes do planeta. Entre os fatores que podem estar contribuindo para explicar o aumento de registro de tais eventos, pode-se citar a expansão da ocupação humana em áreas de risco. Os impactos das adversidades atmosféricas podem ser intensificados quando há interferência das ações antrópicas nas condições naturais do meio ambiente. Constituem exemplos dessas alteraçôes aquelas provocadas pelo desmatamento, pela agricultura e pecuária, e pelos assentamentos humanos, tanto nas encostas do relevo como nas margens dos cursos d'água e planícies litorâneas.

Em escala planetária, as inundaçôes, vendavais, furacôes, terremotos e tsunamis são alguns dos eventos naturais que trouxeram grandes prejuízos em diversas áreas, afetando um número cada vez mais crescente de pessoas. Tais eventos apresentam intensidades diferentes e geram efeitos distintos, resultando, na maioria das ocorrências, em mortes e destruição generalizada. Esses eventos naturais podem causar sérios impactos negativos, tais como inundaçóes bruscas provocadas por chuvas torrenciais, efeitos destrutivos causados por vendavais, rajadas de vento de alta intensidade, precipitaçóes de granizo, tornados e furacóes, os quais têm causado enormes destruiçóes em regiōes litorâneas, devastando cidades inteiras, como têm ocorrido em diversas outras partes do mundo e frequentemente divulgados pelos meios de comunicação.

Desastre natural tem sido caracterizado como um fenômeno de origem natural que causa distúrbio, podendo resultar em uma situação de perigo. Nesse sentido, o perigo que resulta do evento natural é o potencial de desencadear um desastre, sendo considerado desastre natural quando há perdas humanas, econômicas e ambientais que vão além da capacidade das pessoas atingidas de enfrentarem este perigo, resultando em prejuízos diversos para as sociedades afetadas (UNDP, 2004). Os desastres naturais são eventos relacionados com a geodinâmica terrestre externa ou interna. Os de causa externa são os fenômenos atmosféricos, meteorológicos e/ou hidrológicos que ocorrem na atmosfera terrestre, como os de causa eólica, que são os vendavais, ciclones tropicais, furacóes e tornados. Ocorrem devido a temperaturas extremas, que são as ondas de frio intenso, nevascas, granizos e ondas de calor; precipitações pluviais e inundaçôes, enchentes e inundaçóes litorâneas; e reduçáo de precipitaçáo de chuva, provocando estiagens. Os relacionados com geodinâmica terrestre interna são as forças atuantes nas camadas superficiais e profundas da litosfera, como os terremotos, abalos sísmicos, maremotos e tsunamis; as erupçôes vulcânicas; e o intemperismo, incluindo erosão e acomodação do solo, que são os deslizamentos, quedas e tombamentos de terras (Castro et al., 2003).

Estudos relacionados aos desastres naturais apontam que, até a década de 1970, estes foram considerados sinônimos de eventos naturais, como os terremotos e as erupções vulcânicas. Até então, as pesquisas eram focadas nas resistências das estruturas físicas para suportarem esses tipos de desastres. A partir dos anos 1980, com a atuaçáo de pesquisadores das ciências sociais e humanas, iniciou-se outra abordagem sobre o assunto, observando-se a capacidade das pessoas de sofrerem o impacto e de se recuperarem de sua perda ou dano sofrido. Atualmente o foco das pesquisas relacionadas a eventos extremos têm sido também no desenvolvimento social e econômico (UNDP, 2004). O foco no desenvolvimento social e econômico, relacionados aos eventos extremos, desencadeou a ênfase na prevenção, a qual contribui de forma intensa para minimizar os impactos que podem ser causados pelos desastres naturais.

Através de medidas preventivas, é possível evitar danos decorrentes desses fenômenos ou, pelo menos, minimizá-los, com planejamento, pesquisas, estudos prévios e avaliação de riscos. A prevenção torna possível a redução dos prejuízos que os desastres naturais poderão vir a causar; todavia, para prevenir-se de um desastre, é preciso conhecer-lhe as causas e consequências para definir quais são as medidas mais apropriadas a serem adotadas quando ocorrerem. Nesse caso, a prevenção passa a ser feita através da compreensão dos fatores e processos que desencadeiam os fenômenos naturais. Da mesma forma, a prevenção pode dar condiçóes para a resiliência da sociedade quanto a tais eventos (Marcelino, 2008).

Este estudo aborda a percepção dos atores sociais residentes na planície costeira do Extremo Sul de Santa Catarina (municípios de Balneário Gaivota, Passo de Torres, Santa Rosa do Sul, São João do Sul e Sombrio) onde ocorreram eventos adversos que causaram desastres tanto no meio rural quanto no meio urbano do litoral. Investiga também como está organizada a administração municipal no sentido de alertar a população sobre a ocorrência de possíveis eventos adversos.

Entre os eventos meteorológicos extremos recorrentes na área de estudo, destacam-se: tempestades de granizo, vendavais, furacôes, ciclones tropicais, enchentes, alagamentos e inundaçóes. Ao longo de décadas, esses eventos provocaram grandes estragos e prejuízos para a população residente nesses municípios costeiros. Em 2004, na região Sul de Santa Catarina, ocorreu, inclusive, um evento extremo denominado por especialistas de "furacáo". Esse evento de grande intensidade gerou enormes danos materiais e, segundo moradores da regiâo, provocou pânico e ficou marcado na memória coletiva (Herrmann, 2007).

De acordo com os depoimentos, entre os danos provocados nessa região pelos eventos adversos, destacamse, no meio rural, a destruiçáo das lavouras tradicionais de banana, arroz e fumo, além de instalaçôes rurais, incluindo galpóes e estufas para secagem das folhas de fumo.

Esta pesquisa apresenta, através de relatos e depoimentos orais de pessoas que viveram eventos extremos nos municípios citados, a percepção dessas pessoas sobre esses eventos.

\section{DESASTRES NATURAIS EM SANTA CATARINA}

No Brasil há alteraçóes climáticas que são consideradas fenômenos naturais. São ocorrências, denominadas El Niño e La Niña, que provocam oscilaçóes das temperaturas da superfície do mar. Esses acontecimentos provocam alteraçóes no clima da terra e são consideradas normais, pois estudos concluíram que já existem há milhares de anos. No Brasil, tais acontecimentos provocam precipitaçôes em algumas regiōes e ausência de chuvas em outras (Marengo, 2006). 
Quanto ao fato de as atividades humanas provocarem ou não alteraçóes nos eventos climáticos, Marengo (2006: 137) escreve: "Projeções dos modelos climáticos permitem a geração de cenários de clima no futuro, mas ainda não distinguem ou separam os efeitos da variabilidade natural do clima da variabilidade induzida pelo homem".

Ainda, de acordo com o Intergovernmental Panel on Climate Change (IPCC) (2012), as mudanças climáticas podem ser o resultado de alteração no clima, podendo ser devidas a processos internos naturais ou, ainda, por forças externas e até por alteraçôes humanas.

No Brasil, há evidências de que não são somente os fenômenos naturais que causam as alteraçóes ocorrentes em diversas regióes. As mudanças resultantes do uso e ocupação do solo com a substituição das florestas por culturas anuais, pastagens e agricultura também têm provocado mudanças nas vazóes de importantes bacias hidrográficas, como é o caso da regiāo Sul do Brasil (Marengo, 2006).

No estado de Santa Catarina, localizado na região Sul do Brasil, o relevo do litoral e a dinâmica atmosférica influenciam as variaçóes climáticas locais, tornando essas áreas mais susceptíveis a desencadearem desastres naturais. As adversidades atmosféricas que ocorrem com mais frequência no litoral de Santa Catarina são caracterizadas por vendavais, chuvas com granizos, tornados, marés de tempestades, inundações bruscas e graduais (Monteiro \& Mendonça, 2007). Tais eventos naturais são assim caracterizados: (a) vendavais ou tempestades - perturbaçóes que ocorrem de forma acentuada, alterando o estado normal da atmosfera. "Deslocamento violento de uma massa de ar, de uma área de alta pressão para outra de baixa pressão" (Castro et al., 2003:18-21). São ventos fortes, cujas velocidades variam entre " 88,0 a $102,0 \mathrm{~km} / \mathrm{h}$ ", com chuvas e, às vezes, com granizo; b) ciclones extratropicais - ventos com velocidades entre "102,0 a 120,0 km/h". Também são acompanhados com chuvas fortes e geralmente causam imensas ondas no mar; (c) vendavais extremamente intensos, furacôes, ciclones tropicais - ventos tão fortes que atingem velocidades superiores a "120,0 km/h" (Castro et al., 2003:18-21). Dessa forma, quando os ventos atingem uma velocidade muito além do normal, o evento que ocorre é um furacão. Este é caracterizado como "um sistema de baixa pressão (ciclone) intenso que geralmente se forma sobre os oceanos nas regióes tropicais" (Kobiyama et al., 2006:72).

Os vendavais podem levar a violentas tempestades, sendo caracterizados também por desastre natural. Como podem vir acompanhados não só por chuvas intensas, mas também por queda de granizo, os vendavais acabam provocando inundaçóes, alagamentos, destelhamentos e destruição de plantaçôes, podendo também provocar mortes de pessoas (Herrmann, 2007).

Outra adversidade atmosférica ocorrente no litoral de Santa Catarina é o granizo, definido como precipitação em forma de esfera, que "[...] são os pedaços irregulares de gelo". As tempestades de granizo, ou chuvas de pedra, também podem causar desastres. Ocorrem devido ao estado do tempo que, quando está muito quente e úmido, carrega para cima massas de ar saturadas de vapor que, ao se resfriarem em altitude, acabam gerando enormes nuvens de tempestade. A chuva gerada cai em forma de pedras de gelo. A chuva de granizo pode destruir plantações inteiras e, nas áreas urbanas, danificar os telhados das habitaçóes (Herrmann, 2007:105).

De Acordo com Monteiro (2001: 77), em Santa Catarina "[...] tanto os episódios de muitas chuvas, como os de pequenas estiagens, podem ser intensificados em função da atuação dos fenômenos El-Niño e La-Niña, respectivamente”.

Em Santa Catarina, a agricultura é muito afetada pela ocorrência de granizo. Ocorrem também desastres relacionados com o aumento das precipitaçóes pluviais, como inundaçóes, enchentes e alagamentos, eventos que serão a seguir caracterizados (Herrmann, 2007).

Inundaçóes são transbordamentos de água de rios, lagos e açudes. Ocorre o extravasamento quando a vazão é maior do que a capacidade de descarga do corpo d'água. As inundaçóes podem ser graduais, bruscas e litorâneas. As graduais ocorrem quando a água se eleva de forma lenta e previsível, escoando gradualmente; as bruscas, quando há fortes chuvas, intensas e concentradas, provocando a elevação das águas de forma súbita. As bruscas atingem uma área de impacto bem menor do que as inundaçóes graduais, pois, embora estas sejam mais lentas, geralmente abrangem maiores extensóes. As inundações litorâneas, por sua vez, são geradas através da invasão do mar em áreas interiores, também chamadas de marés de tempestade (Castro et al., 2003; Kobiyama et al., 2006; Herrmann, 2007).

Enchentes, ou cheias, são definidas como a elevação do nível da água no canal de drenagem devido ao aumento da vazão. Nesse caso, o nível d'água atinge a cota máxima do canal, porém, sem extravasar (Carvalho et al., 2007). Quando não houver transbordamento, mesmo o rio ficando com nível d'água elevado, o que ocorre é uma enchente, e não uma inundação (Kobiyama et al., 2006).

Alagamentos são águas acumuladas pelas fortes chuvas nas estradas e ruas de cidades que têm sistemas de drenagem deficientes. A redução da infiltração da água nos solos urbanos pode ser provocada por "[...] impermeabilização do solo, pavimentação de ruas e construção de calçadas", entre outros (Castro et al., 2003:51).

A ocorrência de enchentes e inundaçôes está associada às chuvas intensas, embora existam razóes que acentuam os efeitos adversos dos eventos atmosféricos. Em uma planície litorânea submetida a índices pluviométricos intensos, a tendência é desencadear inundação, mas muitas vezes a causa pode estar associada ao processo de expansão urbana em áreas ribeirinhas. A vegetação natural ao longo dos corpos de água tem sido substituída por edificaçōes, não permitindo que a água pluvial seja infiltrada, gerando, assim, o acúmulo de água e o aumento do escoamento superficial. Os leitos dos rios nas áreas urbanizadas geralmente contêm entulhos, dificultando a vazão da água, o que propicia o transbordamento das margens. As ocupaçóes do solo das áreas urbanas, contrariando a legislaçáo ambiental, também contribuem para a ocorrência de inundaçóes quando são instaladas nas planícies aluviais sujeitas a inundaçóes (Herrmann, 2007).

As adversidades atmosféricas geralmente causam impactos negativos nos locais onde ocorrem. As principais consequências negativas são: residências danificadas ou totalmente destruídas; habitantes desabrigados, feridos e mortos; sistemas viários destruídos ou danificados. Em áreas 
rurais, há destruição de lavouras e também de edificaçóes. Em Santa Catarina, inúmeros desastres são causados pela ocorrência de granizo. Além disso, os municípios litorâneos desse estado sofrem prejuízos devido às marés de tempestades (Herrmann, 2007).

Em março de 2004, a população que vive no litoral sul de Santa Catarina foi surpreendida pelo furacão Catarina, que causou danos severos em diversos municípios do estado. $\mathrm{O}$ evento iniciou com ventos constantes, de aproximadamente $50 \mathrm{~km} / \mathrm{h}$, alcançando até $120 \mathrm{~km} / \mathrm{h}$, acompanhados de forte precipitaçáo. $\mathrm{O}$ mar avançou mais de 70 metros na faixa litorânea, ultrapassando as dunas frontais, e atingiu casas situadas na orla. Os danos mais comuns estáo relacionados às edificaçóes, infraestruturas urbanas, agricultura, flora e fauna, além de afetar dezenas de milhares de pessoas. Na área rural, os maiores prejuízos ocorreram nas culturas de milho, arroz, banana e em hortifruticulturas comumente cultivadas na regiấo atingida. De forma geral, as áreas mais intensamente afetadas pelo Catarina foram as residências de pessoas de baixa renda familiar, principalmente as casas de madeira. (Marcelino et al., 2005:20).

\section{3. ÁREA DE ESTUDO}

A área de estudo está constituída pelos municípios localizados no entorno da lagoa de Sombrio: Balneário Gaivota, Passo de Torres, Santa Rosa do Sul, São Joáo do Sul e Sombrio, no Extremo Sul de Santa Catarina/Brasil (Figura 1). Essa área apresenta $720 \mathrm{~km}^{2}$ de área e abriga 56.557 habitantes (IBGE, 2010).
Essa regiâo é constituída por uma planície costeira, inserida no bioma de mata atlântica, localizado entre o Extremo Sul da Serra Geral e o Oceano Atlântico, com predominância de ecossistemas pertencentes às planícies quaternárias, formadas por depósitos arenosos. $\mathrm{Na}$ área predominam restingas, lagoas costeiras e banhados. Há também floretas quaternárias formando pequenos capóes. A planície está em crescente expansão pelo uso e ocupaçáo da terra por edificaçôes e agricultura. São realizadas principalmente as lavouras de fumo, arroz e milho, além da silvicultura, com plantaçóes de eucaliptos e pinus, e lavouras de banana são realizadas nos morros (Bitencourt et al., 2011b; Bitencourt \& Marimon, 2010).

\section{METODOLOGIA}

Foram realizadas entrevistas com atores sociais dos municípios da área de estudo: Balneário Gaivota, Passo de Torres, Santa Rosa do Sul, São João do Sul e Sombrio. As entrevistas ocorreram em duas etapas. Na primeira, foram entrevistadas famílias (98 entrevistados) que residem em áreas que já foram afetadas por desastres ambientais nos municípios. Para esta amostra foi aplicado um questionário com questôes abertas. No momento da entrevista, todos os presentes na residência foram convidados a participar. Nas áreas rurais, a média de participantes entrevistados em uma residência foi de cinco pessoas, enquanto na área urbana a média foi de duas pessoas por família. Quando foram questionadas sobre eventos no passado, os idosos das famílias entrevistadas foram os mais participantes, relatando
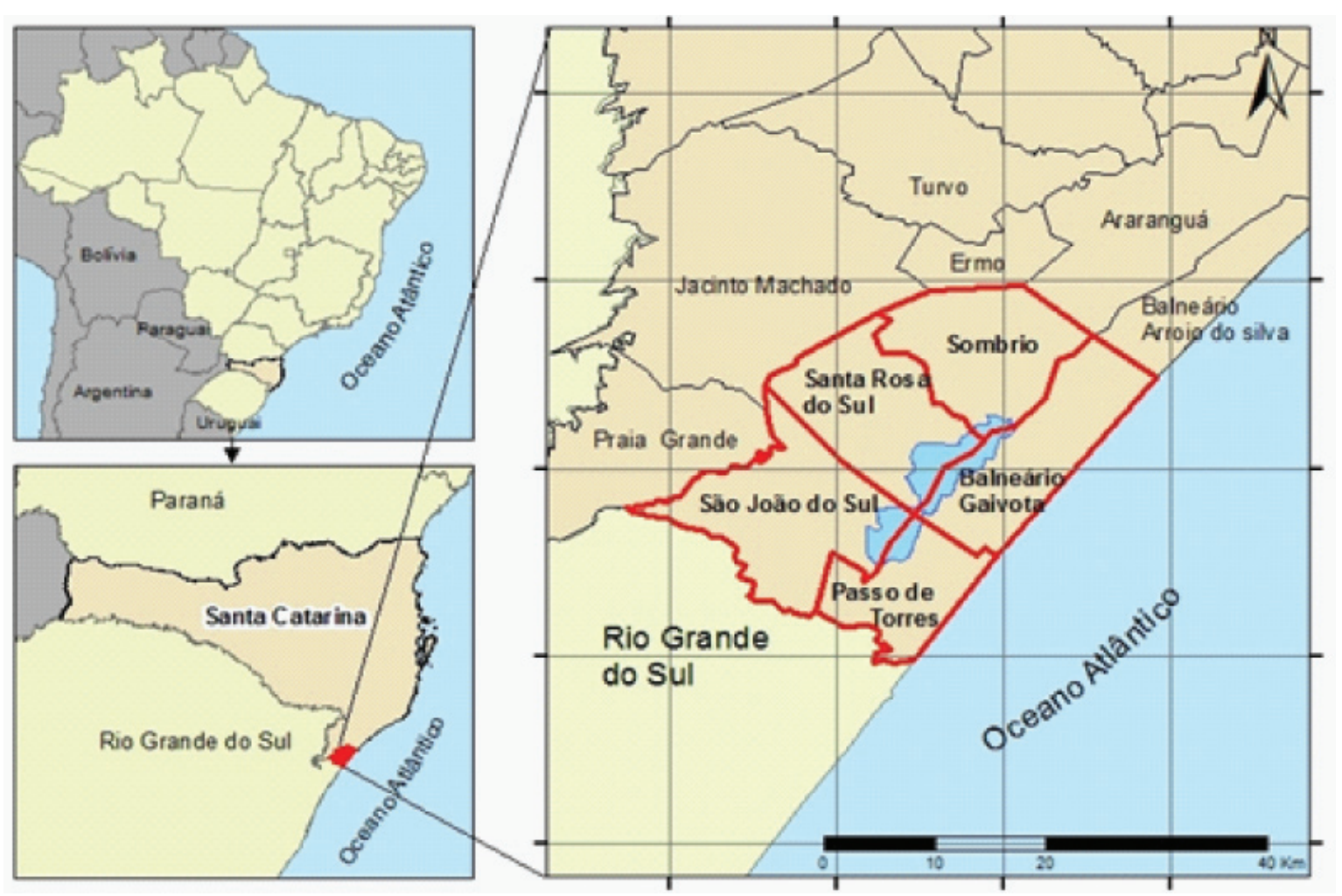

Figura 1. Área de Estudo

Figure 1. Study Area

Fonte: Bitencourt et al. (2011a) 
amplamente suas histórias. Em relação às propriedades das áreas rurais, como apresentam tamanho de até 15 hectares, estas podem ser consideradas como pequenas propriedades familiares.

$\mathrm{Na}$ segunda etapa, após entrevistarmos as famílias que sofreram danos, vários responderam que não sabiam o que fazer na hora do evento (para onde correr, para quem pedir socorro, etc.). Também foram entrevistadas 12 pessoas responsáveis pela administração dos diversos municípios, visando conhecer os procedimentos adotados para atender a população em relação a esses eventos.

As entrevistas visaram compilar e organizar a informação acerca da percepção sobre o impacto dos eventos naturais nas comunidades locais e obter informação sobre as ações das administraçóes municipais relacionadas ao período anterior, durante e depois da ocorrência dos eventos adversos.

\section{RESULTADOS}

Nesta seção são expostos os resultados das entrevistas referentes à percepção dos atores sociais sobre os efeitos dos eventos adversos que causaram desastres naturais na região. As repostas referentes ao termo enchente, na verdade, relatavam as inundações ocorrentes na região. Nesta mesma seção, são apresentados os resultado das entrevistas realizadas na administração municipal.

\subsection{Eventos extremos que causaram desastres naturais: percepçáo do tempo}

Em relação aos eventos que são presenciados no município, os entrevistados citam os ventos fortes com chuva e granizo como sendo o evento mais desastroso e o que mais tem ocorrido na região. Além disso, citam também o mar revolto. Um entrevistado de Passo de Torres comentou: " $O$ que mais me vem na memória é o Catarina. Foi o que mais durou, teve um tempo maior de destruição aqui".

Os relatos mais citados apontam para perdas materiais: "Perdi minha casa no Catarina"; "Perdi o telhado da casa"; "O vendaval derrubou todo o nosso bananal". Outro entrevistado citou que o Catarina estragou os galpóes e estufas; a safra não, porque não era época do fumo. "Em São João do Sul, um vendaval forte provocou danos na fiação de iluminação elétrica, o Catarina deixou o município uma semana sem energia para toda a populaçáo", conforme relatado por funcionários da Cooperativa de Eletricidade (CEPRAG) que atua no município.

Já no município de Sombrio, percorrido pelo rio da Lage, e em São João do Sul, cortado pelos rios do Sertão e Mampituba, as respostas salientam, além das tempestades de ventos com chuva e granizo, a ocorrência de inundaçôes pelos transbordamentos dos rios.

Em relação a esses eventos, uma família entrevistada na área rural do município de São Joâo do Sul respondeu: "Sempre plantamos arroz na beira do rio e sempre sofremos com as enchentes, pois destroem toda a plantação". Outro entrevistado respondeu: "Perco uma parte, quando não, toda a plantação de arroz por causa das enchentes".

Em Sombrio, uma família que reside nas proximidades do rio relatou ter perdido todos os móveis com a inundação que ocorreu.
Em relação ao tempo que vem ocorrendo os eventos, quase todos os entrevistados tinham alguma história para contar. Uma família de entrevistados em Sanga D’Areia comentou: "Há mais ou menos uns 30 anos presenciamos um vendaval muito forte aqui, que derrubou até algumas estufas de fumo".

Em São João do Sul, uma família respondeu: "As tempestades de vento com granizo sempre teve, mas nós nunca vimos tão forte quanto o Catarina aqui". Em relação às inundaçóes, uma família que reside no bairro Glorinha, que faz margem com o Rio Mampituba, disse: "Em 1974 teve uma enchente que causou a morte de muitas pessoas aqui e em Praia Grande. Em 1982 a enchente derrubou quase todas as estufas de fumo daqui da região e de Praia Grande. A enchente de 2007 também destruiu plantaçóes e algumas casas aqui".

\subsection{Frequência dos eventos ao longo do ano e principais danos}

A maioria dos entrevistados citou que os vendavais ocorrem mais no começo do inverno e no início do verão, ou seja, quando há mudança de estação. Já em relação às inundaçôes, disseram que não há uma época definida para ocorrerem. Os entrevistados de São João do Sul relataram que não há época específica para a ocorrência das inundaçóes, pois é algo imprevisível, ocorre com bastante frequência.

Os eventos que têm causado mais danos na regiáo, segundo a maioria das pessoas, são os vendavais com granizo. Em relação às inundaçóes, uma entrevistada de Sombrio disse: "A enchente vem devagarzinho, dá para vigiar e tirar as coisas do lugar, tirar os animais. O vento não dá, pois não avisa, vem e leva até as telhas da casa".

Em relação aos prejuízos ocorridos na área rural, a destruiçấo das lavouras de arroz, banana e fumo foi a mais citada pelas famílias de agricultores entrevistados, como pode ser observada em alguns relatos: "Tive muito prejuizo, a perda de safra de arroz. Com a enchente, tudo fica escuro, $e$ a água, turva, e deixa somente um pântano. Toda a plantação fica perdida", comentou um entrevistado de São João do Sul. $\mathrm{Na}$ área rural desse município, os principais danos foram nas lavouras de arroz pelas inundaçôes, que são recorrentes. Também na região os vendavais já destelharam muitas casas e galpóes.

Em Sombrio, as inundaçóes nas margens do Rio da Lage, no Bairro São José, já destruíram os móveis de duas das casas da rua Vereador Protásio Cunha. Uma entrevistada comentou: "Quando ocorrem as enchentes, nós ficamos ilhados e temos que erguer tudo dentro de casa".

Em Santa Rosa do Sul, uma família do bairro Pontáo afirmou que seu bananal foi destruído duas vezes pelo vento forte, antes do Catarina, além de este ter prejudicado bastante a plantação. O Catarina destruiu muitas lavouras na redondeza, enquanto na área urbana da cidade o que mais ocorreu foi o destelhamento das casas.

No mesmo município, no local chamado Barro Preto, o agricultor entrevistado comentou a respeito da lavoura de fumo: "Já tive três vezes minha lavoura destruida por vento com granizo. O telhado da estufa de fumo já foi arrancado pelos ventos". 
Em Passo de Torres, um grupo de pescadores entrevistados respondeu: "A pesca tem muito prejuizo por causa dos ventos. Com o mar revolto, temos que ficar esperando e ai náo podemos trazer o peixe".

Entre os principais prejuízos que foram relatados em Balneário Gaivota, um entrevistado respondeu: "Na minha casa voou todo o telhado e a antena parabólica, mas teve um vizinho meu que ficou somente com o terreno sem a casa que estava em cima."

\subsection{Reaçáo das pessoas aos eventos e prevenção}

A pergunta sobre qual é a reação quando enfrenta um evento e se conhece algum meio para se prevenir teve sempre como primeira resposta: sensação de medo, muito pânico e espanto.

O que causa mais insegurança e medo é o vento. " $O$ vento vem e leva tudo que tem pela frente", disse uma família moradora do centro da cidade de Balneário Gaivota. "Me sinto impotente, em pânico, com muito medo das tormentas de vento". "Depois daquela coisa muito feia que foi o Catarina, agora, quando vem uma tempestade de vento e chuva, dá muito medo em todos lá em casa", relataram outros dois entrevistados.

Ainda em relação ao evento Catarina, uma família de agricultores que trabalha na lavoura de fumo em São João do Sul disse: "Quando veio o Catarina, tivemos uma noite muito atormentada, mas, nas plantaçóes de fumo, o que mais causa prejuizo são as chuvas com granizo, que destroem as folhas do pé de fumo".

Em Passo de Torres, uma família de pescadores entrevistada respondeu: "Quando veio o Catarina, tivemos muito medo, pois foi a pior coisa do mundo que aconteceu aqui. Foi apavoramento, a gente não sabia o que fazer".

Em Santa Rosa do Sul, um dos depoimentos de uma família entrevistada respondeu: "Peço a Deus, pois não há o que fazer, e após a tragédia é muito trabalho depois para recomeçar tudo". Uma agricultora falou: "Não tem o que fazer, tem que esperar a tormenta de vento passar e trabalhar depois para recuperar tudo". Um entrevistado residente no centro da cidade disse: "O vendaval com chuva de pedra de gelo que deu, não sei se em 2009 ou 2010, mas foi bem depois do Catarina, nós aqui em casa ficamos acordados à noite, cobrimos os móveis com plásticos, pois arrancou as telhas, e choveu na casa toda. Ficamos todos em pé a noite toda, esperando amanhecer".

Já em relação às inundaçóes, em São João do Sul, disse um agricultor: "Quando começa a chover, fico com muito medo, então não durmo e fico vigiando o rio, tenho medo de perder as lavouras, a gente planta uma vez por ano, e, se tem enchente, tudo fica perdido. Agora, quanto é tempestade de vento, é pior ainda, dá muito medo, ele aparece do nada, não dá tempo de vigiar".

Mesmo nos locais em que ocorrem inundaçóes, as pessoas dizem que têm mais medo do vento. Segundo um agricultor, em São João do Sul, "os ventos são bem piores, porque vêm de surpresa, e o rio, a gente pode ficar vigiando quando ele vai subindo". Uma entrevistada que reside na área urbana comentou: "Antes do Catarina eu tinha medo das enchentes, mas agora tenho medo dos ventos fortes".
Todos afirmam que não há o que se fazer, mesmo porque não existe informação meteorológica confiável localmente. Os relatos apontam que: "Não há avisos em lugar nenhum"; "Cada um por si, Deus por todos"; "Os avisos vêm da meteorologia, pela televisäo, nada especifico do municipio".

Um entrevistado de Passo de Torres comentou: "Aqui em casa a gente corre pra onde tem laje, que é no teto do banheiro".

Em São João do Sul, uma família de agricultores disse: "Nas enchentes, tiramos os móveis de casa e os animais". Já em Sombrio, uma entrevistada que reside nas margens do rio falou: "Fico olhando, e, se o rio vai subir, nós erguemos as coisas dentro de casa".

\subsection{Tipos de assistência prestada e conhecimento sobre quem procurar}

A pergunta sobre o oferecimento de algum tipo de ajuda, por parte do governo, do município ou de outro, quando ocorreu algum evento, e se sabem a quem pedir ajuda indicou o seguinte quadro.

Alguns dos entrevistados disseram que não receberam nada, mas outros disseram que já ganharam telhas. Em Santa Rosa do Sul, um plantador de fumo disse: "O município não ajuda para a lavoura quando tem uma destruição pelos vendavais. Só se fizer seguro particular, mas é muito caro, e não existe seguro para o vento, só para as chuvas de pedras de gelo". Outra agricultora de São João do Sul relatou: "Nunca recebi ajuda. Quando a gente perde a plantação, é cada um por si. As pessoas se viram por conta própria". Um entrevistado de Passo de Torres afirmou: "Eu tive o meu fundo de garantia liberado e recebi doação de telhas para recobrir a casa toda". Por fim, em Sombrio, uma família que mora às margens do Rio da Lage disse: "Ainda não tivemos ajuda. Aqui é só promessas".

Os moradores dizem não saber a quem pedir ajuda, após a ocorrência dos eventos. De acordo com uma família de agricultores: "Para aqueles que têm as lavouras seguradas, têm a quem buscar apoio financeiro, porém são poucos, pois é muito caro fazer seguro das lavouras, além do incentivo das lavouras de fumo estar diminuindo muito".

Os entrevistados comentaram que algumas pessoas foram ajudadas por prefeituras, com aquisição de telhas para cobrir suas casas, destelhadas pelos vendavais.

A maioria respondeu que não sabe a quem pedir ajuda. Alguns citaram os Bombeiros.

\subsection{Comunicação prévia sobre os eventos}

A indagação sobre se há avisos, através de rádio, igreja, escola, etc., antes de ocorrer algum evento extremo, e se existem informaçóes sobre como proceder com segurança nessas situaçóes apresentou o que segue: "Fomos pegos de surpresa pelos ventos fortes e chuvas com pedras grandes que quebrou o telhado de muitas casas". "Não avisam quando tem alguma coisa assim, mas nós olhamos a previsão do tempo na TV", disseram os entrevistados. Tal situação mostra que não há informação para prevenir a população local sobre os eventos que podem ocorrer na regiấo.

Em Passo de Torres, São João do Sul, Santa Rosa do Sul e Sombrio, os entrevistados disseram que foram avisados pelo rádio: "Avisar é dificil por aqui, mas sobre o Catarina avisaram 
pelo rádio, mas ninguém acreditou no aviso", disse uma família de agricultores.

Em Balneário Gaivota, um entrevistado falou: "Acho que depois do Catarina a defesa civil ficou mais alerta".

Em Passo de Torres, o presidente da Colônia dos Pescadores expôs: "Pela guarda costeira, os barcos têm marômetro, chega no porto e a gente já sabe se vem tempestade. Agora tem a base da pesca que avisa os pescadores, e eles avisam os outros quanto tem um temporal, mas isso é mais quando o mar pode ficar revolto, perigoso para os pescadores. O Catarina foi avisado pela TVe pelo rádio".

As respostas foram unânimes de que não há informação nos municípios sobre como proceder com segurança em uma adversidade atmosférica.

\section{6. Áreas do município mais afetadas pelos eventos}

Em Santa Rosa do Sul, os eventos ocorrem em todo o território municipal, conforme os entrevistados. De acordo com o presidente do Conselho do Desenvolvimento da Agricultura Municipal, desde o evento Catarina, as chuvas com ventos fortes e granizo têm ocorrido com maior frequência. Ele relata que, com o evento Catarina e os outros que ocorreram depois, houve perda de aproximadamente $70 \%$ da produçâo de fumo e arroz, e a destruição de cerca de 400 galpões na região.

Em relação às inundações que acontecem em São João do Sul, de acordo com os entrevistados, os locais mais afetados, são os bairros Passo Negro, Timbopeba, Glorinha, Querência e Sanga Danta. Um depoimento de um morador de São João do Sul aponta: "De 2007 pra cá, tivemos mais de cinco enchentes aqui na Timbopeba". Em Sombrio ocorrem inundaçóes no Bairro Vila São José, mas apenas nas margens do rio.

\subsection{Fatores que causam os desastres naturais}

De acordo com os entrevistados, as causas da ocorrência dos desastres naturais foram as mudanças climáticas, sendo o aquecimento global o mais citado. Outros disseram que é por causa do desmatamento: "O homem que está mudando tudo, eu acho que é o desmatamento e excesso de veneno em tudo que é plantado", argumentou um agricultor.

\subsection{Administração municipal na Defesa Civil}

Em relação à administraçấo municipal, quando foi questionada sobre quem era o responsável pela Defesa Civil no município e quais eram as ações que estavam sendo desenvolvidas em cada município para informar a população sobre os eventos, a resposta foi que ainda estavam sendo formadas as respectivas equipes, os coordenadores para a Defesa Civil, bem como os locais onde iriam trabalhar.

$\mathrm{Na}$ administração dos municípios da região, após o evento Catarina houve a intenção de serem criadas as Coordenadorias Municipais de Defesa Civil (COMDEC). Porém, nas prefeituras, as estruturas dessas coordenadorias contavam apenas com um único funcionário, que seria deslocado de outra secretaria para atuar também na Defesa Civil. Um exemplo é o município de São João do Sul: a pessoa que estava na coordenação da Defesa Civil era o secretário do Planejamento. Em Santa Rosa do Sul, o coordenador da Defesa Civil era o secretário da Educação. Este último informou que em Capão da Canoa, município próximo, há uma estação meteorológica que se comunica com o município de Santa Rosa do Sul, alertando sobre os eventos; no entanto, o secretário da Educação informou que é muito complicado avisar a população que pode ocorrer um evento, pois pode causar pânico. Ele relatou que "Houve uma vez que a população foi avisada, através do rádio comunitário, de que ocorreria uma tempestade com ventos fortes, mas nada ocorreu e o povo mostrou revolta".

Com as novas administrações das prefeituras, que iniciaram em 2013, estão sendo selecionadas as pessoas que irão trabalhar na Defesa Civil. No momento atual, ainda estão sendo treinadas as pessoas/equipes que assumirão as coordenadorias e outras funçóes.

\section{DISCUSSÃO E CONCLUSÓES}

Os eventos que causaram desastres naturais mais recorrentes nos diversos municípios da regiáo têm sido os ventos fortes acompanhados por chuva e granizo. Entre estes eventos, mereceu destaque o "furacão Catarina". Os ventos com grande velocidade e o mar atingindo picos muito altos de onda provocaram ressaca em boa parte do litoral Sul catarinense. O "Catarina" constituiu um evento extremo com dimensão nunca antes vivenciada pela população (Hermann, 2007). Embora agricultores tenham relatado que antes do Catarina já havia acontecido um vendaval táo forte que derrubou plantações de bananas e estufas de fumo.

Em relaçáo à época de ocorrência dos eventos, embora a maioria tenha citado que os vendavais ocorrem em mudança de estação, de acordo com uma análise dos eventos extremos, realizada no período de 1980 a 2003 por Marcelino et al. (2007), em Santa Catarina, houve anos em que foram registrados desastres naturais em todos os períodos sazonais.

Considerando o tempo que esses eventos vêm ocorrendo, já deveria existir mais informação para as pessoas que vivem em regióes afetadas. Conhecendo os eventos adversos, tornase melhor lidar com os problemas relacionados (Marcelino, 2008). Muitas áreas do município de São João do Sul ficaram embaixo d'água com a inundação gradual que ocorreu no ano de 1974. Esse evento traumatizou diversos moradores da região devido aos prejuízos causados e ao medo que sentiram não apenas por esse evento, mas também por outros de menor proporção bastante recorrentes. Tal situação constituise numa das grandes afliçóes dos que moram próximo ao Rio Mampituba, embora os que ali moram continuem trabalhando em suas plantaçóes até nas margens do rio. Os ventos e as fortes chuvas sobre a região que está próxima à Serra Geral geram correnteza forte, o que facilita a ocorrência das inundaçôes. As águas tornam-se violentas e com muito barro, atingindo as terras dos moradores, destruindo casas, levando animais, devastando as plantações, arrastando tudo por onde passam (Bauer, 2009).

De acordo com a percepção dos entrevistados, o principal dano causado pelos eventos extremos nas áreas urbanas é o destelhamento de casas, e, nas áreas rurais, os principais impactos estão relacionados às lavouras e as estruturas das construçóes rurais, principalmente as estufas e os galpóes. Os prejuízos causados pelo furacấo Catarina foram tão intensos 
que, segundo informaçóes da Defesa Civil do estado, quase 30 mil pessoas foram atingidas. Muitos ficaram desalojados, desabrigados, deslocados, além disso, pessoas ficaram feridas e até ocorreram mortes. No meio rural, houve diversos prejuízos nas construções - estufas, galpôes, silos, engenhos e aviários - e nas plantaçóes, principalmente de arroz, milho, banana, fumo e reflorestamento. Isso aponta para o desenvolvimento de estratégias diferenciadas também nesse sentido por parte da Defesa Civil e das administraçóes municipais. Embora as pessoas que residem em áreas rurais tenham uma relação diferenciada com o meio ambiente, pois têm um olhar diferente sobre o que ocorre com o clima, deveria haver meios eficazes de informar o que é possível fazer para que não percam toda a safra em uma adversidade. Uma estratégia poderia ser, por exemplo, instruir para não investir somente em uma cultura anual.

Em São João do Sul, já houve muitos prejuízos provocados pelas inundaçóes, afetando principalmente as lavouras da população que vive na proximidade dos rios. De acordo com Bauer (2009), moradores relatam que o rio já foi motivo de temor e prejuízos. As terras que o margeiam possuem áreas mais férteis pelo fato de o rio depositar matéria orgânica quando há alagamentos, deixando o solo rico em nutrientes e propiciando o cultivo de lavouras com menor emprego de fertilizantes. Daí o motivo das perdas, pois as lavouras também estão situadas nas margens do rio. Conforme Herrmann (2007), as inundaçôes causam grandes prejuízos materiais e emocionais, desabrigando moradores, devastando plantaçóes, inclusive levando à morte de pessoas por afogamento. Em sua análise dos eventos extremos ocorridos durante o período 1980 ao início de 2004, a autora relatou que foram as inundaçóes as responsáveis pelo maior número de desabrigados e mortos em Santa Catarina.

Embora, em todos os municípios deste estudo, o evento apontado como causador de grandes danos foram os vendavais, além destes, os que têm causado mais perdas para os agricultores são os associados a chuva e granizo.

Angel (2007) salienta que deveria haver mais atençáo voltada para as áreas vulneráveis à ocorrência de desastres naturais, e não somente para os eventos de grande magnitude. As análises de vulnerabilidade deveriam ir além das condiçóes sociais, abordando os aspectos ambientais que existem em cada local. Entretanto, de acordo com Prieto (2007: 12), prevenir para que as pessoas não fiquem expostas a ameaças de origem natural não é tão simples, pois resultam em atividades dispendiosas e difíceis de serem realizadas, como por exemplo, quando é necessária a remoção de comunidades de uma área que oferece risco de inundação. Quando é possível planejar a cidade para que uma área que possa oferecer risco seja substituída por outra, a prevenção é viável e possível. No caso das plantações em margens de rios em São João do Sul, a prevenção seria viável e possível.

É importante observar que a estrutura da Defesa Civil, que está sendo montada nos municípios, deveria levar em conta as peculiaridades de cada local. Sobre essa questão, em curso realizado pela Empresa de Pesquisa Agropecuária e Extensão Rural de Santa Catarina (EPAGRI) nas cooperativas da agricultura familiar no sul de Santa Catarina, município de Criciúma, o coordenador regional da Defesa Civil destacou, em março de 2013, a importância da capacitação dos agricultores na prevenção aos desastres naturais.

Sobre a reação dos que foram afetados pelos desastres naturais, o resultado das entrevistas mostrou que, mesmo sendo eventos que ocorreram há muito tempo, as pessoas que tiveram algum tipo de sofrimento têm a lembrança muito viva da ocorrência e demonstram em suas falas muito medo de que voltem a acontecer. Em relação ao extravasamento dos rios que provocam as inundaçóes em São João do Sul, conforme Bauer (2009), os moradores dessa localidade relatam situações traumáticas em relação à inundação ocorrida na região do Rio Mampituba. O medo pode estar associado não somente à ocorrência do evento, mas à falta de conhecimento sobre ele, por não existirem informaçóes sobre o que deve ser feito para lidar com essa situação.

Embora seja muito importante a ajuda quando ocorre um desastre natural, mais importante ainda é a informaçáo para prevenir os efeitos do evento. No momento atual, em que existem disponibilidades de informações por diversos meios de comunicação, é impossível conceber que ainda existem pessoas que carecem de informaçóes nos municípios afetados pelos eventos adversos que geram desastres naturais. Avisos e informaçôes são fundamentais para essas situaçôes. Poderia existir informação para as populaçóes sobre as áreas mais vulneráveis e o porque de serem vulneráveis, bem como sobre as alternativas que podem ser dadas para que tais áreas sejam evitadas. Se a administração municipal não dá suporte para avisar a população antes de acontecer um evento extremo, a própria população deveria ser instruída para procurar se informar sobre esses acontecimentos a fim de mobilizar-se a tempo.

É importante também que as pessoas sejam informadas acerca dos fatores que causam os desastres naturais, como desmatamento de encostas e de margens de rios e assoreamento de cursos de água. Kobiyama et al. (2006:38) destacam a importância da participação da sociedade na minimização dos impactos causados pelos eventos adversos. Para esses autores, a participação e a informação são fundamentais para a minimização das causas surgidas com os eventos extremos. Eles destacam a importância do Gerenciamento de Desastres Naturais incluindo duas metas: "(1) entender os mecanismos dos fenômenos naturais e (2) aumentar a resistência da sociedade contra esses fenômenos".

Em relação aos fatores que causam os desastres naturais, os entrevistados percebem que há influência antrópica no meio. Isso pode mostrar que as pessoas estão refletindo e percebendo que são agentes modificadores, podendo ter certa influência nas alteraçôes locais através de seus atos.

Acerca da ação da Defesa Civil nos municípios, conforme os entrevistados na administração de Balneário Gaivota, Passo de Torres, Santa Rosa do Sul, São João do Sul e Sombrio, com a mudança da administração, decorrente das eleiçôes municipais em 2012, as coordenaçôes para a Defesa Civil ainda estão em fase de estruturação em todas as cidades citadas. Ainda está sendo providenciada a estrutura física (salas) para as coordenaçóes de cada município. Além disso, as pessoas que estavam na gestão anterior não são as mesmas que estão assumindo a coordenação da Defesa Civil nas novas administraçóes municipais.

Sobre esta questão, o coordenador regional da Defesa Civil da região Sul destacou que, nas prefeituras, muitos 
dos que estão coordenando a Defesa Civil estão em cargos comissionados, ou seja, estão no cargo de coordenação enquanto o prefeito eleito estiver no cargo. Dessa forma, enquanto não existir um quadro permanente nas prefeituras para a Defesa Civil, a cada quatro anos (tempo de mandato de um prefeito) entram novas equipes não capacitadas para realizar a proteção civil. Relativo a essa questâo, mesmo tendo acontecido diversos desastres naturais na regiáo, ainda não há plano de ações ou planos de contingência nesses municípios. Conforme relatos dos entrevistados, é urgente que as pessoas saibam a quem comunicar quando ocorrerem eventos extremos, bem como saibam obter informaçóes de como proceder com segurança em tais situaçóes.

Com base na lei 12.608/2012, a Coordenadoria Municipal de Proteção e Defesa Civil (COMPDEC) é o órgão responsável pelas atividades de proteção e defesa civil no âmbito municipal. Essa coordenadoria deve dispor de estruturas próprias para exercer a função que lhe compete. As competências municipais, definidas por essa legislação federal, são: coordenar as ações do Sistema Nacional de Proteção e Defesa Civil (SINPDEC), incorporar as açóes de proteção e defesa civil no planejamento municipal e identificar e mapear as áreas de risco de desastres, não permitindo novas ocupaçōes nessas áreas. A COMPDEC deve, ainda, informar à população sobre áreas de risco e ocorrência de eventos extremos e sobre as açôes emergenciais quando ocorrem desastres, além de outras ações importantes, no sentido de melhorar a situação daqueles que ocupam áreas sujeitas a eventos extremos. Ainda em relação à criação dessa coordenação, a Portaria n. 912-A, de 29 de maio de 2008, do Ministério da Integração Nacional, condiciona o recebimento de recursos financeiros mediante a comprovação da existência e funcionamento do Órgão Municipal de Proteção e Defesa Civil como uma forma de pressionar a administração municipal para estruturar-se frente a essas ocorrências. Além disso, é importante destacar que não somente em concordância com a lei citada, é necessário, e de extrema importância, que a Defesa Civil esteja em funcionamento em cada município, para amparar a população, ajudando-a no enfrentamento dos desastres naturais.

A gestão de risco de desastres naturais deve ser parte integrante do planejamento e implementaçáo do desenvolvimento local, a qual, por sua vez, deve ser integrada em planos nacionais de desenvolvimento. Ainda, as experiências da populaçáo local no enfrentamento de um desastre natural são muito importantes, pois fornecem informações para os planos de gestão de riscos locais (IPCC, 2012).

A informação aliada a treinamentos, que aqui não ocorre, mas já é regular em outros países, é de grande importância para a minimização dos impactos de eventos extremos, pois pode dar condiçóes para que haja prevenção de acidentes envolvendo vidas humanas e de animais. Para reduzir os desastres naturais, são fundamentais a capacitação das pessoas e a informação, via meios de comunicação de massa, sendo estes de extrema importância para o enfrentamento dos eventos extremos (Carvalho et al., 2007).

No Brasil, têm aumentado as açóes em prol da prevenção de desastres naturais, como a integraçáo das políticas de governo com as políticas setoriais, no sentido de reforçar as açôes de proteção e defesa civil para melhorar a gestão de risco e de desastres no país, incluindo as políticas relacionadas ao "ordenamento territorial, desenvolvimento urbano, saúde, meio ambiente, mudanças climáticas, gestão de recursos hídricos, geologia, infraestrutura, educação, ciência e tecnologia" (Furtado et al., 2012:31). Com isso, pode-se concluir que já existem alguns avanços legais, mas ainda há muito a ser feito a fim de que a população se sinta protegida e segura frente à ocorrência de eventos adversos.

Em Santa Catarina, embora existam as Coordenadorias Regionais de Defesa Civil que estáo localizadas em quatorze regióes do estado, como a da região Sul que está sediada em Criciúma, ainda urge a necessidade de estas levarem informaçóes para as populaçóes que são afetadas regularmente por eventos extremos, como mostra esta pesquisa.

\section{CONSIDERAÇÓES FINAIS}

De acordo com os resultados obtidos pelas entrevistas realizadas no litoral do Extremo Sul de Santa Catarina, têm ocorrido vários desastres naturais na região, causando prejuízos de diversas magnitudes.

As ocorrências de desastres naturais, principalmente de inundaçôes, estão vivas na memória das pessoas desde épocas remotas. Embora esses eventos adversos estejam sendo registrados e divulgados com mais frequência na atualidade, o evento natural mais observado foi o excesso de chuvas, inclusive com granizo e ventos fortes, o que já era visto no passado. No meio rural, o dano mais relatado foi a destruiçáo das lavouras, como hoje acontece.

Quanto aos efeitos dos eventos extremos, foi percebida uma diferença entre as percepçóes das pessoas que residem e trabalham no meio rural e as das que residem e trabalham no meio urbano. As que vivem em meio rural têm sua preocupação totalmente voltada para o seu meio de vida, seu sustento através do cultivo da lavoura, então qualquer destruição de parte de sua plantação vai afetar a parte financeira. Famílias do meio rural relataram que haviam perdido toda a safra de fumo devido a uma ocorrência de uma chuva com granizo. Foi visível que o destelhamento de casas não os afeta como qualquer alteração em suas lavouras. Já no meio urbano, as pessoas relataram a perda de parte de sua residência, principalmente o destelhamento das casas, mas têm seus trabalhos, sua renda mensal, que não é prejudicada, como acontece com as pessoas que sobrevivem da agricultura.

Ao falarem do medo que sentiam, tanto as pessoas do meio rural quanto as do meio urbano mostraram ter medo e sensação de estarem desprotegidas em situaçóes de eventos extremos.

Em relação às estratégias de mobilização da sociedade frente aos eventos extremos, tanto no meio rural como no meio urbano, não se verifica diferença, pois não há nenhuma estratégia de prevenção por parte das famílias entrevistadas.

Ainda, em relação à adaptação aos eventos, percebe-se que as famílias que sofrem com as inundaçôes estáo acostumadas e demonstraram não sentirem tanto medo como sentem quando ocorrem os vendavais.

Os relatos de moradores de áreas atingidas por eventos extremos, no caso dos municípios citados, mostra que 
a população desses locais não tem recebido dos órgãos responsáveis pela administração dos municípios informaçôes sobre os eventos extremos que ocorreram ou possam vir a ocorrer na região. Provavelmente, se a previsáo já existisse, danos maiores teriam sido evitados. Em relaçâo a algum tipo de apoio por parte dos órgãos competentes, como o fornecimento de telhas ou de lonas para as residências destelhadas, esse tipo de ajuda ocorre tanto no meio rural quando no meio urbano.

Vale lembrar a importância do desenvolvimento de métodos mais participativos para a gestão e planejamento municipais, principalmente os que envolvem a prevenção de desastres naturais, que seriam táo importante para as populaçóes que vivem em áreas sujeitas a eventos extremos.

A criaçáo e o funcionamento da coordenaçáo para a Proteção e Defesa Civil dos municípios, conforme determina a legislação, ainda está em estruturação. Embora existam mecanismos institucionalizados de proteçáo civil no estado, faltando apenas demandar responsabilidades efetivas aos municípios estudados.

Ainda merece destaque a questão de os responsáveis pela defesa civil de cada município estudado não serem funcionários permanentes, e sim pessoas de cargos temporários. Estas, embora recebam treinamentos para atuarem na defesa civil do município, por serem seus cargos temporários, não poderão permanecer neles quando houver novas eleições. Frente a essa questão, percebe-se a necessidade de criaçáo de cargos permanentes e treinamento das pessoas que irão atuar na Defesa Civil desses municípios de forma mais efetiva.

Além disso, mesmo que já tenham ocorridos diversos eventos extremos no Extremo Sul de Santa Catarina, ainda não existe uma cultura de informação e prevenção desses eventos na região, nem por parte das pessoas que lá vivem nem por parte de órgãos de comunicação.

\section{AGRADECIMENTOS}

À Coordenação de Aperfeiçoamento de Pessoal de Nível Superior (CAPES) pelo apoio financeiro, às famílias entrevistadas e às administraçôes municipais da área de estudo.

\section{REFERÊNCIAS BIBLIOGRÁFICAS}

Ángel, M.F.O. (2007) - Articulación de la Gestión Ambiental y la Gestión del Riesgo. In: Tiempo para entregar el relevo: reducción del riesgo de desastres desde la perspectiva de la gestión ambiental, ordenamiento territorial, finanzas $e$ inversión pública. 276 p., San José, C. R.: 1ª ed. Grupo Internacional Recursos Del Sur, IRG. ISBN 978-9968500-00-5

Bauer, V.S. (2009) - Preservação de matas ciliares e educação ambiental: um estudo de caso na bacia hidrográfica do Rio Mampituba em São João do Sul, Santa Catarina. Criciúma, SC. 185p., Dissertação de Mestrado, Universidade do Extremo Sul Catarinense, Criciúma, SC, Brasil. Não publicado.

Bitencourt, N.L.R.; Centenaro, K.S.; Marimon, M.P.C. (2011a) - A percepção ambiental como instrumento de análise da qualidade ambiental: estudo de caso no litoral sul de Santa Catarina, Brail. Costa Rica, Revista Geográfica de América Central, Número Especial EGAL, pp. 1-15. Disponível em: http://www.revistas.una.ac.cr/ index.php/geografica/article/view/2674

Bitencourt, N.L.R.; Lalane H.C; Rocha, I.O. (2011b) - O processo de ocupação dos espaços costeiros do extremo sul de Santa Catarina, Brasil. Costa Rica, Revista Geográfica de América Central, Número Especial EGAL, pp. 1-15. Disponível em: http://www.revistas.una.ac.cr/index.php/ geografica/article/view/2531

Bitencourt, N.L.R.; Marimon, M.P.C. (2010) - A Problemática do Uso e Ocupaçáo da Zona Costeira do Sul de Santa Catarina, Brasil. IV Congresso Brasileiro de Oceanografia - CBO 2010, FURG, Rio Grande. AOCEANO 1: 674-677.

Castro, A.L.C.de; Calheiros, L.B.; Cunha, M.I.R.; Bringel, M.L.N.daC. (2003) - Manual de Desastres Naturais. 174p., Ministério da Integração Nacional, Brasília. Disponível em: http://www.esdec.defesacivil.rj.gov.br/ documentos/publicacoes_da_secretaria_nacional/6_ desastres_naturais_volI.pdf.

Carvalho, C.S.; Macedo, E.S.de; Ogura, A.T. (org.). (2007) - Mapeamento de Riscos em Encostas e Margem de Rios. Ministério das Cidades, IPT, Brasília. Disponível em: http://www.cidades.gov.br/images/stories/ ArquivosSNPU/

Furtado, J.; Oliveira, M.de; Dantas, M.C.; Souza, P.P.; Panceri, R. (2012) - Capacitação Básica em Defesa Civil. 122p., Centro Universitário de Pesquisa e Estudos sobre Desastres CAD/UFSC, Florianópolis, Santa Catarina. ISBN 978-85-64695-31-3 Disponível em: http://www. defesacivil.mg.gov.br/conteudo/arquivos/manuais/ Livro_Defesa_Civil_Completo.pdf

Herrmann, M.L.P. (org.). (2007) - Atlas de Desastres Naturais do Estado de Santa Catarina. 146p., IOESC, Florianópolis.

Instituto Brasileiro de Geografia e Estatística. (2010) - Cidades@. Censo 2010. IBGE, Disponível em: http://www.ibge.gov.br/cidadesat/topwindow.htm?

IPCC (2012) - Managing the Risks of Extreme Events and Disasters to Advance Climate Change Adaptation. A Special Report of Working Groups I and II of the Intergovernmental Panel on Climate Change [EM ITÁLICO]. Cambridge University Press, Cambridge, UK, and New York, NY, USA, 582 pp. ISBN 978-1-10702506-6 Disponível em: http://ipcc-wg2.gov/SREX/ images/uploads/SREX-All_FINAL.pdf

Lei n. 12.608, de 10 de abril de 2012. Institui a Política Nacional de Proteção e Defesa Civil - PNPDEC; dispóe sobre o Sistema Nacional de Proteção e Defesa Civil - SINPDEC e o Conselho Nacional de Proteção e Defesa Civil - CONPDEC; autoriza a criação de sistema de informaçóes e monitoramento de desastres (EM ITÁLICO). Disponível em: http://www.planalto.gov.br/ ccivil_03/_Ato2011-2014/2012/Lei/L12608.htm

Kobiyama, M.; Mendonça, M.; Moreno, D.A.; Marcelino, I.P.V.de O.; Marcelino, E. V.; Gonçalves, E.F.; Brazetti, L.L.P.; Goerl, R.F.; Molleri, G.S.F.; Rudorff, F. de M. (2006) - Prevenção de desastres naturais: conceitos básicos. Organic Trading, Curitiba: Ed. Organic Trading, 124p. Disponível em: Disponível em: http:// 
www.labhidro.ufsc.br/Artigos/Livro\%20(Prevencao\%20 de\%20Desastres\%20Naturais).pdf.

Marengo, J.A. (2006) - Mudanças climáticas globais e seus efeitos sobre a biodiversidade: caracterização do clima atuale definição das alteraçôes climáticas para o território brasileiro ao longo do século XXI. Brasília: MMA, 212 p. ISBN 857738-038-6 Disponível em: http://www.mma.gov.br/ estruturas/imprensa/_arquivos/livro\%20completo.pdf

Marcelino, E.V.; Rudorff, F.M.; Marcelino, I.P.V.O.; Goerl, R.F.; Kobyama, M. (2005) - Impacto do Furacão Catarina sobre a região sul catarinense: monitoramento e avaliação pós-desastre. Revista Geografia, 30 (3): 559-582.

Marcelino, I.P.V.de O.; Molleri, G.S.F.; Goerl, R.F.; Marcelino, E.V.; Moreno, D. A.; Rudorff, F.M. (2007) - Adversidades Atmosféricas no Estado de Santa Catarina no período de 1980 a 2003. In: Herrmann, Maria L. P. (org.), Atlas de Desastres Naturais do Estado de Santa Catarina, 146p., IOESC, Florianópolis, SC, Brasil.

Marcelino, E.V. (2008) - Desastres naturais e geotecnologias: conceitos básicos. 40p., INPE, Santa Maria, Brasil. Disponível em: http://mtc-m18.sid.inpe.br/col/sid.inpe. br/mtc-m18@80/2008/07.02.16.22/doc/publicacao.pdf

Monteiro, M.A; Mendonça, M. (2007) - Dinâmica Atmosférica no Estado de Santa Catarina. In: Herrmann, Maria L. de P. (org.). Atlas de Desastres Naturais do Estado de Santa Catarina, IOESC, Florianópolis, Brasil.

Monteiro, M.A. (2001) - Caracterização climática do estado de Santa Catarina: uma abordagem dos principais sistemas atmosféricos que atuam durante o ano. GEOSUL, Florianópolis: Editora da UFSC, 31(16): 69-78.
Portaria n. 912-A, de 29 de maio de 2008. Disponível em: http://www.defesacivil.pr.gov.br/arquivos/File/publicacoes/ PORTARIAN912ACOMDEC.doc

Prieto, J.P.S. (2007) - El desafío de la Gestión de Riesgo como estrategia de intervención multisectorial y participativa al servicio del desarrollo. In: Tiempo para entregar el relevo: reducción del riesgo de desastres desde la perspectiva de la gestión ambiental, ordenamiento territorial, finanzas e inversión pública. San José, C. R.: $1^{\text {a }}$ ed. Grupo Internacional Recursos Del Sur, IRG. ISBN 978-9968-500-00-5. Disponível em: http://www. redulac.net/redulac/images_documentosypublicaciones/ tiempo_para_entregar/CAPITULO $\% 201 \% 20$ EL $\% 20$ DESAFIO\%20DE\%20LA\%20GESTION\%20DE\%20 RIESGOS.pdf

Severo, D. L. (1994) - Estudo de casos de chuvas intensas no Estado de Santa Catarina. São José dos Campos: INPE, 118p. INPE-5682-TDI/568. Disponível em: http://mtc-m17.sid.inpe.br/col/sid.inpe.br/MTC13@80/2005/08.26.17.51/doc/INPE-5682-TDI568 pdf.pdf

United Nations Development Programme (2004) - A Global Report: Reducing Disaster Risk a Challenge for Development. 146p., Printed by John S. Swift Co., New York, USA. ISBN 92-1-126160-0 Disponível em: http://www.undp. $\mathrm{org} /$ content/dam/undp/library/crisis\%20prevention/ disaster/asia_pacific/Reducing\%20Disaster\%20risk $\% 20$ a\%20Challenge $\% 20$ for $\% 20$ development.pdf 